\title{
Personalizing heart failure management in chronic kidney disease patients
}

\author{
Debasish Banerjee (D) ${ }^{1,2}$ and Angela Yee-Moon Wang ${ }^{3}$ \\ ${ }^{1}$ Renal and Transplantation Unit, St George's University Hospitals NHS Foundation Trust, London, UK, ${ }^{2}$ Cardiovascular Clinical Academic \\ Group, Molecular and Clinical Sciences Research Institute, St George's, University of London, London, UK and ${ }^{3}$ Department of Medicine, \\ Queen Mary Hospital, University of Hong Kong, Hong Kong
}

Correspondence to: Debasish Banerjee; E-mail: debasish.banerjee@stgeorges.nhs.uk

\section{ABSTRACT}

Chronic kidney disease (CKD) in heart failure (HF) patients is common, present in $49 \%$, and is associated with a higher mortality hazard ratio [2.34 (95\% confidence interval $2.20-2.50$ ); $\mathrm{P}<0.001]$ and multiple hospital admissions. The management of $\mathrm{HF}$ in $\mathrm{CKD}$ can be challenging due to drug-induced electrolyte and creatinine changes, resistance to diuretics and infections related to device therapy. Evidence for improvement in mortality and HF hospitalizations exists in HF with reduced ejection fraction (HFrEF) in Stage 3 CKD patients from randomized controlled trials of angiotensin-converting enzyme inhibitor (ACEi) and mineralocorticoid receptor antagonist therapy but not in dialysis patients, where higher doses can cause hyperkalaemia. Evidence of improvement in cardiovascular death and HF hospitalizations has emerged with the angiotensin receptor neprilysin inhibitor ivabradine and more recently with sodium-glucose cotransporter inhibitors in HFrEF patients with CKD Stages 1-3. However, these studies have excluded CKD Stages 4 and 5 patients. Evidence for $\beta$-blocker therapy exists in CKD Stages 1-3 and separately in haemodialysis patients. Cardiac resynchronization therapy reduces HF hospitalizations and mortality in patients with CKD Stages 1-3 but has not been shown to do so in CKD Stages 4 and 5 or dialysis patients. Internal cardioverter and defibrillator therapy in HFrEF patients has been shown to be beneficial in CKD 3 patients but not in dialysis patients, where it is associated with high rates of infection. For HFpEF patients with CKD, therapy is symptomatic, as there is no proven therapy for improvement in survival or hospitalizations. HF patients with end-stage kidney disease with fluid overload may benefit from peritoneal dialysis. A multidisciplinary, personalized approach has been associated with better care and improved patient satisfaction.

Keywords: CKD, dialysis, heart failure, hyperkalaemia, peritoneal dialysis

\section{INTRODUCTION}

Patients with heart failure (HF) and chronic kidney disease (CKD) are often frail and elderly, with very different needs, depending on age, co-existing comorbidities and expectations. An elderly multimorbid individual with CKD and HF may be keen to enjoy their remaining life free from symptoms and hospital admissions, whereas a young individual with the same condition may wish to live longer and contribute positively at home and work. A personalized, collaborative management approach tailored to the patient's needs and life goals should be the way forward. This review describes the burden of HF with $\mathrm{CKD}$, the updated evidence behind therapy and the benefits of a patient-centred multidisciplinary approach. For this review we conducted a literature search using the MESH terms 'heart failure' and 'kidney disease' or 'kidney failure', particularly looking for randomised controlled trial evidence. The search resulted in 260 studies that were reviewed for the purpose of this article. Studies mentioned in the recent consensus reports were also reviewed.

\section{EPIDEMIOLOGY OF HF WITH CKD AND VICE VERSA}

The results from meta-analyses of cohort, registry and randomized controlled HF studies indicated that $32 \%$ of patients suffered from CKD, but the prevalence of CKD was higher (49\%) when excluding the two specific registry studies [1]. The prevalence of CKD was observed to be higher in acute HF patients (53\%) compared with chronic HF patients (42\%) [1]. In our own experience with acute HF patients, the incidence is $\sim 47 \%$ [2].

The common causes of CKD in patients with HF are hypertension, diabetes and atherosclerotic renovascular disease [3]. In a normal physiological state, the heart and kidney are 


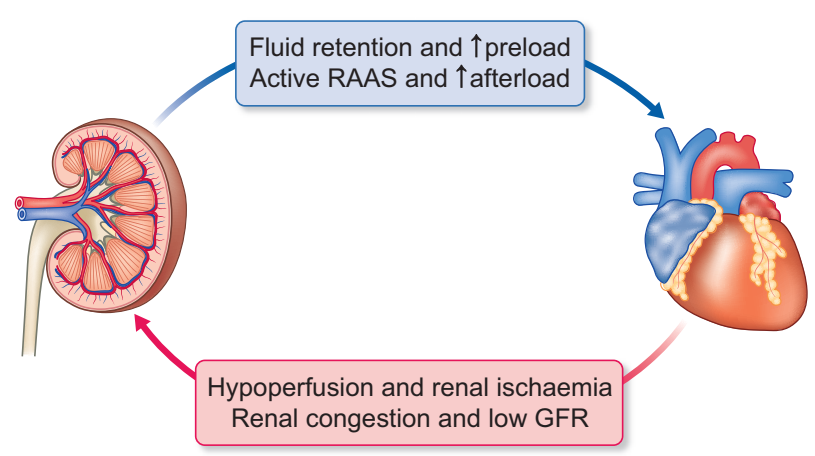

FIGURE 1: The interdependence of the kidney and heart in HF patients with CKD.

interdependent for their functions and in disease states they adversely affect each other's function [4]. A poorly pumping heart fails to deliver adequate oxygen to the kidney, causing ischaemic injury, and a failing kidney retains salt and water to add to the burden on the heart (see Figure 1).

\section{PROGNOSIS OF HF PATIENTS WITH CKD}

Clinically important adverse outcomes to be considered in patients with HF include the number and duration of hospitalizations, mortality and poor quality of life and functional status due to symptoms. The prognosis of HF has improved over time but remains poor compared with other chronic conditions. In the recently completed Empagliflozin Outcome Trial in Patients with Chronic Heart Failure and Reduced Ejection Fraction (EMPEROR-Reduced) trial in patients with New York Heart Association (NYHA) Classes II-IV, HF with reduced ejection fraction (HFrEF) treated with placebo [age $66 \pm 11$ years, EF $27 \pm 6 \%$, diabetes $50 \%, 70 \%$ on angiotensinconverting enzyme inhibitor (ACEi) or angiotensin receptor blocker (ARB), 73\% on mineralocorticoid receptor antagonist (MRA), $95 \%$ on $\beta$-blockers, $44 \%$ on device therapy], all-cause mortality was $10.7 \%$ /year and hospitalizations were $71 \% /$ year [5]. In a meta-analysis of acute and chronic HF patients, coexisting CKD was associated with a higher risk of death. Mortality was higher in CKD patients compared with nonCKD patients \{hazard ratio [HR] 2.34 [95\% confidence interval (CI) 2.20-2.50]; $\mathrm{P}<0.001\}$ when followed for a mean of $361 \pm 333$ days for acute HF patients and $942 \pm 802$ days for chronic HF patients [1].

\section{PRINCIPLES OF MANAGEMENT OF HF PATIENTS WITH CKD}

The goal of treatment for HF patients is not only to improve survival but also to improve functional status and quality of life. Better symptom control and quality of life may often be of higher priority over prolonged survival in multimorbid HFCKD patients. Recurrent hospitalizations are undesirable, as this impacts the patients' life goals and quality of life and hence prevention of hospitalization is an important treatment outcome. A common indication for hospitalization is breathlessness and oedema, which often requires carefully managed diuretic therapy, as discussed below. Both established and

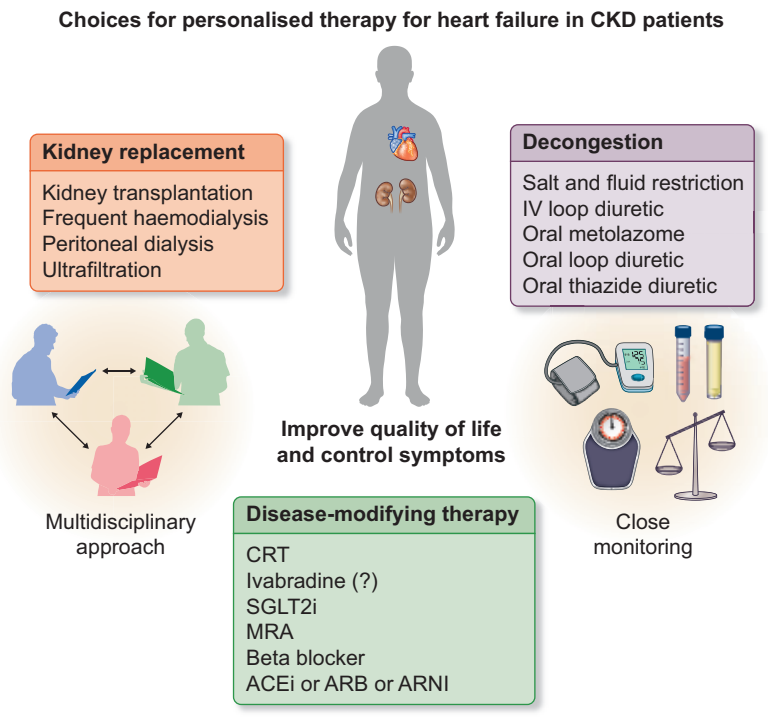

FIGURE 2: The treatment options for HF in CKD patients. The figure shows the treatment choices for HF in CKD patients, including life-prolonging therapy for HFrEF in CKD Stages $1-3$ as the base, decongestion therapy on the right, choices for renal replacement therapy on the left. It also highlights the importance of close collaboration between primary care, HF nurses, cardiologists and nephrologists and close monitoring of blood pressure, weight, fluid balance and laboratory parameters.

newer drug and device therapies that have been shown to improve survival and reduce hospitalization rates in HFrEF patients with CKD are discussed below (Figure 2).

\section{CHALLENGES IN THE MANAGEMENT OF HF PATIENTS WITH CKD}

There are several challenges in the management of HF in the presence of kidney disease, including abnormalities of drug pharmacokinetics, altered drug pharmacodynamics, biochemical abnormalities of electrolytes and infections with device therapy. Abnormalities of drug pharmacokinetics due to poor kidney function are several. Concentrations of certain drugs increase in the blood in CKD due to decreased kidney elimination. In addition, CKD causes abnormalities such as pglycoprotein function increasing the bioavailability of digoxin and cytochrome P450 enzyme function decreasing the clearance of carvedilol and verapamil. Often the available evidence of the exact impact of CKD on drug pharmacokinetics is limited and dose adjustments are difficult.

\section{Diuretic resistance}

The effects of diuretic therapy decrease with worsening kidney function, but the term diuretic resistance is not very well defined. Thiazide diuretics are often ineffective in CKD Stages 4 and 5. Loop diuretics are more effective with lower estimated glomerular filtration rate (eGFR); however, higher doses are necessary with lower GFRs. Loop diuretics work by acting on the sodium-potassium cotransporters on the luminal side of tubular cells in the ascending limb of the loop of Henle. Decreased function of organic anion transporters prevents 
secretion of loop diuretics into the tubular lumen, thereby preventing their action [6].

Initial increase in serum creatinine with initiation of ACEi/ARB and sodium-glucose cotransporter 2 (SGLT2) inhibitor therapy

Studies have shown that the initiation of ACEi therapy may be associated with an initial decline in kidney function before slowing in the progression of kidney disease in both HF and non-HF patients. In the Studies of Left Ventricular Dysfunction [SOLVD] trial, 606 patients (9.5\%) experienced worsening kidney function between baseline and 14 days post-randomization, with a mean decrease in eGFR of $29.2 \pm 9.8 \%$ in the enalapril group and $28.9 \pm 9.3 \%$ in the placebo group. Patients experiencing early worsening kidney failure (WKF) at 14 days had a significant recovery of kidney function by 1 year $(\mathrm{P}<0.0001)$ and the degree of recovery was similar between those assigned to enalapril or placebo $(16.0 \pm 34.1 \%$ versus $18.2 \pm 38.0 \% ; \mathrm{P}=0.52)$. However, patients with worsening kidney function with enalapril had no increase in mortality [HR 1.0 (95\% CI 0.78-1.3); $\mathrm{P}=1.0$ ] as opposed to placebo patients with WKF [HR 1.3 (95\% CI 1.1-1.7); $\mathrm{P}=0.012$ ] [7]. More recently, reanalysis of the SOLVD trial showed that compared with $0 \%$ eGFR decline in the placebo arm as the reference, up to a $10 \%$ decline in eGFR with enalapril was associated with survival benefit [HR 0.87 (95\% CI 0.77-0.99)] while up to a $35 \%$ decline in eGFR was associated with a decreased risk of HF hospitalization [HR 0.78 (95\% CI 0.61-0.98)] [8].

The early worsening of kidney function is related to efferent arteriolar vasodilation and a decrease in filtration pressure at each individual nephron. The lower intraglomerular pressure prevents hyperfiltration in each nephron and protects the glomerulus in the longer term. A similar observation was noted with SGLT2 inhibitor trials. In a trial of $4744 \mathrm{HF}$ patients randomized to dapagliflozin or placebo, there was a higher initial decline in eGFR in the dapagliflozin group than in the placebo group $\left(-3.97 \pm 0.15\right.$ versus $\left.-0.82 \pm 0.15 \mathrm{~mL} / \mathrm{min} / 1.73 \mathrm{~m}^{2}\right)$ [9]. However, thereafter the annual change in the mean eGFR was smaller with dapagliflozin than with placebo $(-1.67 \pm 0.11$ and $-3.59 \pm 0.11 \mathrm{~mL} / \mathrm{min} / 1.73 \mathrm{~m}^{2}$, respectively), for a betweengroup difference of $1.92 \mathrm{~mL} / \mathrm{min} / 1.73 \mathrm{~m}^{2} /$ year (95\% CI $1.61-$ 2.24).

The early worsening of kidney function at 2 weeks is consistent among different SGLT2 inhibitors. This is probably due to tubuloglomerular feedback, whereby increased salt and water delivery to the periglomerular distal tubule causes afferent arteriolar vasoconstriction and a decline in filtration pressure in each glomerulus. The low intraglomerular pressure protects the glomerulus from hyperfiltration.

\section{HYPERKALAEMIA DUE TO ACEi, ARB AND MRA}

Hyperkalaemia is an uncommon side effect of renin-angiotensin-aldosterone system inhibitor (RAASi) therapy in HF with CKD. In the SOLVD trial the incidence of serum potassium $>5.5 \mathrm{mmol} / \mathrm{L}$ with enalapril was $6.4 \%$. The mean eGFR in the trial was $65 \pm 19 \mathrm{~mL} / \mathrm{min} / 1.73 \mathrm{~m}^{2}$ [10]. Use of the ACEi benazepril in advanced CKD was associated with a higher incidence of potassium $>6.0 \mathrm{mmol} / \mathrm{L} \quad(5 \%)$, with baseline eGFR $37 \pm 6 \mathrm{~mL} / \mathrm{min} / 1.73 \mathrm{~m}^{2}$ [11]. Therapy with spironolactone in the Randomized Aldactone Evaluation Study [RALES] study resulted in serious hyperkalaemia in $3.9 \%(>6.0 \mathrm{mmol} / \mathrm{L})$ and $19 \%(>5.5 \mathrm{mmol} / \mathrm{L})$ of patients [12]. The incidence of hyperkalaemia is perhaps higher in haemodialysis patients, as discussed below.

\section{LACK OF EVIDENCE OF DRUG THERAPY IN ADVANCED CKD}

Most clinical trials of $\mathrm{HF}$ exclude subjects with advanced CKD $\left(e G F R<30 \mathrm{~mL} / \mathrm{min} / 1.73 \mathrm{~m}^{2}\right)$. The exclusion criterion in earlier studies was creatine $>177 \mu \mathrm{mol} / \mathrm{L}$ or $>221 \mu \mathrm{mol} / \mathrm{L}[10]$. More recently the exclusion criterion has been either $\mathrm{eGFR}<30 \mathrm{~mL} / \mathrm{min} / 1.73 \mathrm{~m}^{2}$ or $<20 \mathrm{~mL} / \mathrm{min} / 1.73 \mathrm{~m}^{2}$ [5]. Hence patients with CKD Stages 4 and 5 were mostly excluded in randomized controlled trials (RCTs) of HF.

\section{LIFESTYLE CHANGES FOR MANAGEMENT OF HF PATIENTS WITH CKD}

Exercise helps in the improvement of quality of life in patients with HFrEF, as demonstrated in a RCT with 2332 patients exercising for 36 sessions over 3 months [13]. The mean creatinine was $1.2 \mathrm{mg} / \mathrm{dL}$, hence a significant proportion had CKD. Salt restriction is recommended for patients, particularly with fluid overload, but RCT evidence is lacking.

\section{DRUG THERAPY FOR HF WITH REDUCED EF AND CKD (TABLE 1)}

\section{$\beta$-blockers}

Subgroup analysis of general population studies suggests survival benefits with $\beta$-blocker use in subjects with HFrEF and CKD [14-18]. Carvedilol therapy has been shown to improve mortality in HFrEF patients on haemodialysis [19]. The same study suggested improvement in sudden death, which is common in dialysis and advanced CKD patients $[19,20]$.

\section{ACEi or ARB}

There is positive evidence for CKD Stages 1-3 patients from general population studies such as SOLVD and Survival and Ventricular Enlargement (SAVE) on mortality and hospitalizations in HF with CKD. The SAVE trial randomized 2231 patients with a creatinine level up to $221 \mu \mathrm{mol} / \mathrm{L}$, showing an improvement in all-cause mortality with captopril compared with placebo [21]. The SOLVD trial randomized 2569 patients with a creatinine up to $177 \mu \mathrm{mol} / \mathrm{L}$, showing an improvement in all-cause mortality with enalapril compared with placebo [10]. These drugs caused a decline in kidney function that was not associated with an adverse outcome. Hyperkalaemia is an infrequent side effect, the incidence of which increased with worsening kidney function. However, these trials excluded subjects with advanced CKD. The effects of ACEi/ARB in patients on dialysis remain controversial, with one randomized trial suggesting the $\beta$-blocker atenelol was better than the ACEi lisinopril $[22,23]$ while another trial [Fosinopril in Dialysis 
Table 1. Drug and device therapy for HFrEF in patients with CKD, based on available evidence

\begin{tabular}{|c|c|c|c|}
\hline Agents & CKD Stages 1-3 & CKD Stages 4 and 5 & Dialysis \\
\hline$\beta$-blockers & Should be used & May be used & Should be used \\
\hline ACEis & $\begin{array}{l}\text { Should be used, with monitoring of } \\
\text { creatinine and potassium }\end{array}$ & $\begin{array}{l}\text { May be used with monitoring of } \\
\text { creatinine and potassium. Dose } \\
\text { modification may be necessary }\end{array}$ & $\begin{array}{l}\text { No proven benefit, limited } \\
\text { evidence }\end{array}$ \\
\hline MRAs & $\begin{array}{l}\text { Should be used with careful monitor- } \\
\text { ing of potassium }\end{array}$ & $\begin{array}{l}\text { May be used with caution and } \\
\text { monitoring of potassium }\end{array}$ & $\begin{array}{l}\text { No proven benefit, may cause } \\
\text { hyperkalaemia with high dose }\end{array}$ \\
\hline ARBs & Should be used with caution & $\begin{array}{l}\text { May be used with monitoring of } \\
\text { creatinine and potassium }\end{array}$ & $\begin{array}{l}\text { No proven benefits, may cause } \\
\text { hyperkalaemia }\end{array}$ \\
\hline Ivabradine & $\begin{array}{l}\text { May be used with sinus rhythm and } \\
\text { stable on } \beta \text {-blockers }\end{array}$ & Unknown effects & Unknown effect \\
\hline ARNI & May be used instead of ACEi/ARB & No proven benefit & No proven benefits \\
\hline SGLT2 inhibitor ${ }^{\mathrm{a}}$ & $\begin{array}{l}\text { Should be used with or without } \\
\text { diabetes }\end{array}$ & Unknown effects & No proven benefits \\
\hline Hydralazine and iIsosorbide dinitrate & $\begin{array}{l}\text { Should be considered intolerant to } \\
\text { ACE/ARB }\end{array}$ & $\begin{array}{l}\text { May be considered intolerant to } \\
\text { ACE/ARB }\end{array}$ & No proven benefits \\
\hline CRT & $\begin{array}{l}\text { Should be offered to patients with } \\
\text { wide QRS }\end{array}$ & No proven benefit ${ }^{\mathrm{b}}$ & $\begin{array}{l}\text { No proven benefits, increased risk } \\
\text { of infections }\end{array}$ \\
\hline $\begin{array}{l}\text { Internal cardioverter } \\
\text { defibrillator therapy }\end{array}$ & Should be offered patients & No proven benefit & $\begin{array}{l}\text { No benefit in dialysis patients with } \\
E F>35 \% \text {, increased risk of } \\
\text { infections }{ }^{c}\end{array}$ \\
\hline
\end{tabular}

Most evidence is from HF trials that included patients with CKD Stages 1-3 in HFpEF patients with improvement in cardiovascular mortality and HF hospitalizations.

${ }^{\text {a}} \mathrm{SGLT} 2$ inhibitor has significant renal benefits. ${ }^{\text {b }} \mathrm{Few}$ patients were included in the trials. ${ }^{c}$ Based on randomized trial in dialysis patients with $\mathrm{EF}>35 \%$.

(FOSIDIAL)] did not show any difference in survival between ACEI treatment with fosinopril versus placebo over 3 years of follow-up [24].

\section{MRA inhibitor}

There is evidence for benefit in CKD Stages 1-3 patients from general population studies such as RALES and Eplerenone in Mild Patients Hospitalization and Survival Study in Heart Failure (EMPHASIS-HF) on mortality and hospitalizations. In RALES, $48 \%$ of the 1658 patients had an eGFR $<60 \mathrm{~mL} / \mathrm{min} / 1.73 \mathrm{~m}^{2}$ and the risk reduction of death and HF hospitalization was similar for subjects with an eGFR $<60$ or $>60 \mathrm{~mL} / \mathrm{min} / 1.73 \mathrm{~m}^{2}$ [25]. Hyperkalaemia occurred more often in patients with an eGFR $<60 \mathrm{~mL} / \mathrm{min} / 1.73 \mathrm{~m}^{2}$ than those $>60$ $\mathrm{mL} / \mathrm{min} / 1.73 \mathrm{~m}^{2}$ [26]. Deterioration of kidney function was a problem as evidenced by a $>30 \%$ decline in eGFR in $14 \%$ patients in EMPHASIS-HF [27]. Evidence for MRA therapy in CKD Stages 4 and 5 is lacking.

In two recent small RCTs in haemodialysis patients, there was a higher incidence of hyperkalaemia $(>6.5 \mathrm{mmol} / \mathrm{L})$ with spironolactone, and more so with a dose of $50 \mathrm{mg}$ (e.g. 8 of 32 patients) than $25 \mathrm{mg}$ daily (e.g. 4 of 26 patients) $[28,29]$. The incidence of hyperkalaemia $(>6.5 \mathrm{mmol} / \mathrm{L})$ was also higher $(11 \%)$ with eplerenone compared with placebo (2\%) in 154 patients on haemodialysis [30].

\section{Diuretics}

Diuretic therapy can cause adverse effects on blood concentrations of urea, creatinine, sodium and potassium in HF patients with CKD [31]. The changing creatinine and electrolytes may require a decreased dose or cessation of diuretics, which in turn causes fluid overload and hospitalizations.
Kidney venous congestion and consequent kidney dysfunction due to elevated right heart pressure are poorly understood and difficult to manage, requiring escalation of diuretic doses with close monitoring of volume status, body weight and creatinine [32]. The commonly used thiazide diuretics are not effective with advanced CKD and loop diuretics are often used with metolazone as necessary for adequate diuresis. Intravenous diuretics are used for acute decompensated HF. Spironolactone in acute HF patients can be natriuretic and help relieve congestion without significant adverse effects on serum potassium levels [33]. In a carefully conducted study, rapid diuresis was safe in CKD Stages 3 and 4 patients with decompensated HF with high urine volumes of $8425 \mathrm{~mL}$ [interquartile range (IQR) 634110528 ] over $72 \mathrm{~h}$ using furosemide $560 \mathrm{mg}$ (IQR 300-815) and not associated with markers of tubular injury despite a mild increase in serum creatinine [34].

\section{ARNI}

Trials from the general population showed benefits in mortality and hospitalization with confirmed safety in CKD patients with an eGFR $\geq 30 \mathrm{~mL} / \mathrm{min} / 1.73 \mathrm{~m}^{2}$. The benefits of angiotensin receptor neprilysin inhibitor (ARNI) was demonstrated for the first time in a large RCT of $8842 \mathrm{HFrEF}$ patients (eGFR $>30 \mathrm{~m} / \mathrm{min} / 1.73 \mathrm{~m}^{2}$ ) with a reduction in cardiovascular death and HF hospitalization [HR 0.80 (95\% CI 0.73-0.87); $\mathrm{P}<0.001$ ] [35]. There is emerging evidence that ARNIs may slow the progression of CKD as compared with ACEis alone. Side effects such as hyperkalaemia are less common compared with ACEis or ARBs. A meta-analysis of all trials suggested a lower incidence of serious hyperkalaemia (defined as $\mathrm{K}>6.0 \mathrm{mmol} / \mathrm{L}$ ) with ARNI compared with enalarpil or valsar$\tan$ with a pooled relative risk (RR) of 0.76 (95\% CI 0.65-0.89; $\mathrm{P}<0.007)$ and a lower incidence of worsening kidney function [RR 0.79 (95\% CI 0.67-0.95); $\mathrm{P}<0.010$ ] [36]. 


\section{Ivabradine}

Ivabradine, an I(f) current inhibitor, when used in 6658 clinically stable, $\beta$-blocked HFrEF patients with creatinine $<220$ $\mu \mathrm{mol} / \mathrm{L}$, improved cardiac death and HF hospitalizations [37]. This study included a significant number of CKD Stage 3 patients who benefitted, with a risk reduction ratio of $0.82(95 \%$ CI $0.75-0.90 ; \mathrm{P}<0.0001)$. The safety and efficacy of ivabradine in CKD Stage 4 and 5 patients is unknown.

\section{SGLT2i}

The EMPEROR-Reduced trial included patients with HFrEF and CKD with an eGFR $>20 \mathrm{~mL} / \mathrm{min} / 1.73 \mathrm{~m}^{2}$. A total of 1799 of 3730 (48\%) patients had CKD with an eGFR $<60 \mathrm{~mL} / \mathrm{min} /$ $1.73 \mathrm{~m}^{2}$. Cardiovascular death and HF hospitalizations were reduced by 25\% [HR 0.75 (95\% CI 0.65-0.86); $\mathrm{P}<0.001$ ] in the entire population, of which $50 \%$ were diabetics and $73 \%$ had an ejection fraction $[\mathrm{EF}]<30 \%$ [5]. The eGFR decline was slower with empagliflozin compared with placebo ( -0.55 versus $2.28 \mathrm{~mL} / \mathrm{min} / 1.73 \mathrm{~m}^{2} /$ year), for a between-group difference of $1.7 \mathrm{~mL} / \mathrm{min} / 1.73 \mathrm{~m}^{2} /$ year (95\% CI 1.10-2.37; P < 0.001). The primary endpoint was reached in 202/893 with empagliflozin compared with 237/906 with placebo among patients with an eGFR $<60 \mathrm{ml} / \mathrm{min} / 1.73 \mathrm{~m}^{2}$. There was a $50 \%$ (95\% CI 32-77) reduction in the incidence of renalreplacement therapy or sustained loss of eGFR [5].

The Dapagliflozin in Patients With Heart Failure and Reduced Ejection Fraction [DAPA-HF] trial included patients with an eGFR $>30 \mathrm{~mL} / \mathrm{min} / 1.73 \mathrm{~m}^{2}$ and an $\mathrm{EF}<40 \%$. The primary endpoint (worsening HF or cardiovascular death) was reduced by $26 \%$ (95\% CI 65-85) and 40.6\% (1926/4744) of patients had an eGFR $<60 \mathrm{~mL} / \mathrm{min} / 1.73 \mathrm{~m}^{2}$ [9]. The reduction in primary endpoint was similarly observed in CKD and nonCKD patients [HR 0.72 (95\% CI 0.59-0.86) and $\mathrm{HR}=0.76$ (95\% CI 0.63-0.92), respectively]. Serious kidney adverse events occurred in 38 patients $(1.6 \%)$ in the dapagliflozin group and 65 patients $(2.7 \%)$ in the placebo group $(\mathrm{P}=0.009)$.

\section{DEVICE THERAPY FOR HF WITH REDUCED EF AND CKD}

\section{Cardiac resynchronization therapy}

The benefits of cardiac resynchronization therapy (CRT) [with internal cardioverter and defibrillator (ICD)] in patients with eGFR $<60 \mathrm{~mL} / \mathrm{min} / 1.73 \mathrm{~m}^{2}$ were similar to patients with eGFR $>60 \mathrm{~mL} / \mathrm{min} / 1.73 \mathrm{~m}^{2}$. This was demonstrated in 1798 HFrEF patients with QRS duration $>120 \mathrm{~ms}$, eGFR 30-59 in $43 \%$ and $<30 \mathrm{~mL} / \mathrm{min} / 1.73 \mathrm{~m}^{2}$ in $7 \%$ of ICD patients, with reduction in death and hospitalization for $\mathrm{HF}, \mathrm{HR}=0.75$ (95\% CI 0.64-0.87; P < 0.001) [38]. The benefits in CKD Stages 4 and 5 and on dialysis are unknown.

\section{ICD}

Sudden cardiac death (SCD) rates in patients on dialysis and with advanced CKD are high and even higher with HF [20]. There is some evidence of ICD in primary prevention of SCD in HFrEF patients as demonstrated in a trial including CKD Stage 3 patients [39]. However, the risk of infection is high in dialysis

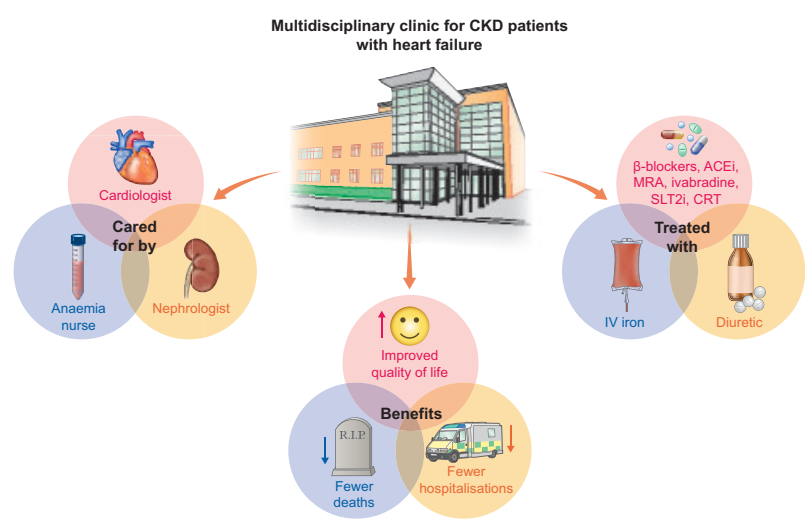

FIGURE 3: The delivery and benefits of a multidisciplinary clinic for CKD patients with HF. The figure shows the caregivers, therapy delivered and possible benefits of a multidisciplinary HF-CKD clinic in a tertiary care centre [43].

patients and recently completed trial in dialysis patients it provided no added benefit in prevention of SCD in patients with $\mathrm{EF}>35 \%$ [40].

\section{MANAGEMENT OF HF WITH PRESERVED EF AND CKD}

HFpEF patients with CKD can be diagnostically challenging, as advanced CKD itself can present with fluid retention and high brain natriuretic peptide [BNP] levels. The presence of significant diastolic dysfunction on echocardiogram helps confirm the diagnosis. These patients may suffer from multiple hospital admissions due to fluid overload requiring high doses of diuretics. There is no proven treatment for HFpPF and CKD that prolongs life or reduces hospitalizations and treatment is mainly symptomatic [41].

\section{MULTIDISCIPLINARY MANAGEMENT}

HF patients with CKD are often frail elderly patients with complex medical needs. They visit multiple health professionals, resulting in fragmented care and conflicting advice. This often results in not starting and/or discontinuing proven therapy. Hence multidisciplinary care at the point of delivery is necessary, particularly having the cardiologist and nephrologist together in one clinic.

We designed a multidisciplinary clinic with a cardiologist and nephrologist (Figure 3) attending the patient in the same room and the anaemia nurse providing intravenous iron and erythropoietin as necessary, as we know that intravenous iron improves symptoms in HFrEF patients, including patients with CKD 3 [42]. The first 124 relatively elderly patients [78.5 years (IQR 68.1-84.4)] over 234 days (IQR 121-441) had an improvement in RAASi therapy [43]. The proportions of HFCKD patients on no RAASi decreased from $41.2 \%$ to $29.9 \%$ and those on single or dual RAASi therapy increased from $45.4 \%$ to $50.5 \%$ and from $13.4 \%$ to $19.6 \%$, respectively $(\mathrm{P}=0.03)$. This was not associated with significant changes in serum potassium or creatinine. Serum ferritin improved from 131.0 to $267.5 \mu \mathrm{g} / \mathrm{L}$ $(\mathrm{P} \leq 0.001)$ and the number of patients with iron deficiency 
decreased from 56.7 to $26.8 \%(\mathrm{P}=0.002)$. In patients with iron deficiency at baseline, $43.6 \%$ received intravenous iron at the same clinic visit, with a significant increase in ferritin level (67.0 to $185.0 \mu \mathrm{g} / \mathrm{L} ; \mathrm{P}<0.001)$. The informal feedback from patients was very positive [44].

\section{PERITONEAL ULTRAFILTRATION IN HF PATIENTS}

Peritoneal dialysis (PD) or ultrafiltration has been used as an alternative strategy to treat subjects with NYHA Classes III and IV HF or end-stage HF and CKD refractory to maximally tolerated medical therapy. Different case series have suggested that peritoneal ultrafiltration significantly reduces hospital stays and improves symptoms, functional status and quality of life [4548]. A previous systematic review of 14 observational studies with 471 patients (average age 71.6 years; diabetes mellitus $47 \%$; NYHA Class III 38.9\%, Class IV 59.8\%; ischaemic cardiopathy 67.8\%; mean left ventricular EF 35\%) suggested significant improvement in NYHA class and a reduction in hospitalizations. Survival at 12 months ranged between $47 \%$ and $95 \%$. Mortality appeared to be associated with diabetes, higher basal eGFR, less change in EF after peritoneal ultrafiltration and less use of icodextrin [49]. Another systematic review of 31 observational studies with 902 diuretic-resistant HF patients showed similar findings that peritoneal ultrafiltration improved left ventricular EF and NYHA class and reduced hospitalization frequency and duration compared with diuretic therapy alone. With follow-up $>1$ year, the overall mortality was $48.3 \%$. Survival was $42.1 \%$ with PD and $45.0 \%$ with extracorporeal therapy [50].

However, so far there has been no RCT that evaluated whether PD or ultrafiltration may impact clinical outcomes and quality of life in these patients. The PD for HF study was a multicentre prospective RCT in subjects with severe diureticresistant NYHA Class III/IV HF and CKD Stage 3/4 already receiving optimal medical treatment who were randomized to either continuation of conventional HF treatment or to additionally receiving peritoneal ultrafiltration with one overnight icodextrin exchange. The primary study endpoint was to examine the change in the 6-min walk test between baseline and 28 weeks. Secondary outcomes were changes in patientreported quality of life as assessed by the Kansas City Cardiomyopathy Questionnaire, 36-item Short Form Health Survey results, hospitalization and mortality. The trial aimed to recruit 130 subjects but was stopped early due to inadequate recruitment. Over a 2-year period, 290 patients were screened, from which only 20 met the inclusion criteria and 10 were recruited. Reasons for ineligibility were fluctuating eGFR, suboptimal HF treatment, frailty, patients being too unwell for randomization, patients' unwillingness to engage in an invasive therapy and suboptimal coordination between cardiology and kidney services, showing the challenges in performing clinical trials in this vulnerable group of subjects [51].

The PD regimen performed for ultrafiltration purposes was very variable. Some reports used one to three daily continuous ambulatory PD exchanges for ultrafiltration while others used two to four sessions weekly using automated PD. The types of PD fluid used were also very variable, from standard glucose solutions to hypertonic glucose solutions or icodextrin. Icodextrin solution has the advantage of being glucose sparing and allowing once daily nocturnal exchange to be performed in these patients. Peritoneal ultrafiltration has also been used successfully in elderly subjects with refractory HF [52].

\section{ONGOING RESEARCH AND TRIALS}

The therapy of $\mathrm{HF}$ in $\mathrm{CKD}$ patients remains challenging and requires more research with established and novel therapies. The evidence for life-prolonging therapy in CKD Stages 4 and 5 and dialysis patients with HF is lacking. Future studies should include patients with advanced CKD and on kidney replacement to help minimize unexpected deaths and hospitalizations. The safety and efficacy of sacubitril/valsartan is being tested in dialysis patients in the Effect of Sacubitril/Valsartan on Cardiovascular Events in Dialysis Patients and Efficacy Prediction of Baseline LVEF Value study (NCT04572724).

Evidence of life-prolonging treatment of HFpEF in early and advanced CKD is lacking. Ongoing studies include FINEARTSHF (NCT04435626), an RCT of finerenone (a non-steroidal MRA) in CKD patients with HFpEF; the Phase IIb Safety and Efficacy Study of Different Oral Doses of BAY94-8862 in Subjects With Worsening Chronic Heart Failure and Left Ventricular Systolic Dysfunction and Either Type 2 Diabetes Mellitus With or Without Chronic Kidney Disease or Chronic Kidney Disease Alone (ARTS-HF), which is recruiting CKD 3 patients and the novel MRA therapy trial Efficacy, Safety and Tolerability of AZD9977 (the novel MRA) and Dapagliflozin in Participants With Heart Failure and Chronic Kidney Disease (MIRACLE; NCT04595370), which will include at least $30 \%$ of patients with an eGFR $<30 \mathrm{~mL} / \mathrm{min} / 1.73 \mathrm{~m}^{2}$. Empagliflozin is being tested in acute $\mathrm{HF}$ patients with an eGFR $>20 \mathrm{~mL} / \mathrm{min} /$ $1.73 \mathrm{~m}^{2}$ in A Study to Test the Effect of Empagliflozin in Patients Who Are in Hospital for Acute Heart Failure (NCT04157751), with kidney failure as a secondary outcome. The possible efficacy of peritoneal ultrafiltration is proposed to be tested in the Peritoneal Ultrafiltration in Cardio Renal Syndrome study (NCT03994874), which may provide further insights in CKD Stages 4 and 5 patients.

\section{CONCLUSION}

HF patients with CKD are common and difficult to treat, despite evidence in HFpEF with CKD Stages 1-3. A multidisciplinary approach with personalized care is the way forward.

\section{CONFLICT OF INTEREST STATEMENT}

None declared.

\section{REFERENCES}

1. Damman K, Valente MA, Voors AA et al. Renal impairment, worsening renal function, and outcome in patients with heart failure: an updated metaanalysis. Eur Heart J 2014; 35: 455-469

2. Jenkins R, Mandarano L, Gugathas $\mathrm{S}$ et al. Impaired renal function affects clinical outcomes and management of patients with heart failure. ESC Heart Fail 2017; 4: 576-584

3. Zannad F, Rossignol P. Cardiorenal syndrome revisited. Circulation 2018; 138: 929-944 
4. Ronco C, Haapio M, House AA et al. Cardiorenal syndrome. J Am Coll Cardiol 2008; 52: 1527-1539

5. Packer M, Anker SD, Butler J et al. Cardiovascular and renal outcomes with empagliflozin in heart failure. N Engl J Med 2020; 383: 1413-1424

6. Felker GM, Ellison DH, Mullens W et al. Diuretic therapy for patients with heart dailure: JACC state-of-the-art review. J Am Coll Cardiol 2020; 75: 1178-1195

7. Testani JM, Kimmel SE, Dries DL et al. Prognostic importance of early worsening renal function after initiation of angiotensin-converting enzyme inhibitor therapy in patients with cardiac dysfunction. Circ Heart Fail 2011; 4: 685-691

8. McCallum W, Tighiouart $\mathrm{H}, \mathrm{Ku} \mathrm{E}$ et al. Acute declines in estimated glomerular filtration rate on enalapril and mortality and cardiovascular outcomes in patients with heart failure with reduced ejection fraction. Kidney Int 2019; 96: 1185-1194

9. McMurray JJV, Solomon SD, Inzucchi SE et al. Dapagliflozin in patients with heart failure and reduced ejection fraction. $N$ Engl J Med 2019; 381: 1995-2008

10. SOLVD Investigators, Yusuf S, Pitt B et al. Effect of enalapril on survival in patients with reduced left ventricular ejection fractions and congestive heart failure. N Engl J Med 1991; 325: 293-302

11. Hou FF, Zhang X, Zhang GH et al. Efficacy and safety of benazepril for advanced chronic renal insufficiency. N Engl J Med 2006; 354: 131-140

12. Vardeny O, Claggett B, Anand I et al. Incidence, predictors, and outcomes related to hypo- and hyperkalemia in patients with severe heart failure treated with a mineralocorticoid receptor antagonist. Circ Heart Fail 2014; 7: 573-579

13. Flynn KE, Piña IL, Whellan DJ et al. Effects of exercise training on health status in patients with chronic heart failure: HF-ACTION randomized controlled trial. JAMA 2009; 301: 1451-1459

14. Effect of metoprolol CR/XL in chronic heart failure: Metoprolol CR/XL Randomised Intervention Trial in Congestive Heart Failure (MERIT-HF). Lancet 1999; 353: 2001-2007

15. The Cardiac Insufficiency Bisoprolol Study II (CIBIS-II): a randomised trial. Lancet 1999; 353: 9-13

16. Packer M, Coats AJ, Fowler MB et al. Effect of carvedilol on survival in severe chronic heart failure. N Engl J Med 2001; 344: 1651-1658

17. Flather MD, Shibata MC, Coats AJ et al. Randomized trial to determine the effect of nebivolol on mortality and cardiovascular hospital admission in elderly patients with heart failure (SENIORS). Eur Heart J 2005; 26: 215-225

18. Lunney M, Ruospo M, Natale $\mathrm{P}$ et al. Pharmacological interventions for heart failure in people with chronic kidney disease. Cochrane Database Syst Rev 2020; 2: CD012466

19. Cice G, Ferrara L, D'Andrea A et al. Carvedilol increases two-year survivalin dialysis patients with dilated cardiomyopathy: a prospective, placebocontrolled trial. J Am Coll Cardiol 2003; 41: 1438-1444

20. Turakhia MP, Blankestijn PJ, Carrero JJ et al. Chronic kidney disease and arrhythmias: conclusions from a Kidney Disease: Improving Global Outcomes (KDIGO) Controversies Conference. Eur Heart J 2018; 39: 2314-2325

21. Pfeffer MA, Braunwald E, Moye LA et al. Effect of captopril on mortality and morbidity in patients with left ventricular dysfunction after myocardial infarction. Results of the survival and ventricular enlargement trial. the SAVE Investigators. N Engl J Med 1992; 327: 669-677

22. Liu Y, Ma X, Zheng J et al. Effects of angiotensin-converting enzyme inhibitors and angiotensin receptor blockers on cardiovascular events and residual renal function in dialysis patients: a meta-analysis of randomised controlled trials. BMC Nephrol 2017; 18: 206

23. Agarwal R, Sinha AD, Pappas $\mathrm{MK}$ et al. Hypertension in hemodialysis patients treated with atenolol or lisinopril: a randomized controlled trial. Nephrol Dial Transplant 2014; 29: 672-681

24. Zannad F, Kessler M, Lehert P et al. Prevention of cardiovascular events in end-stage renal disease: results of a randomized trial of fosinopril and implications for future studies. Kidney Int 2006; 70: 1318-1324

25. Pitt B, Zannad F, Remme WJ et al. The effect of spironolactone on morbidity and mortality in patients with severe heart failure. Randomized
Aldactone Evaluation Study Investigators. N Engl J Med 1999; 341: 709-717

26. Vardeny $\mathrm{O}, \mathrm{Wu} \mathrm{DH}$, Desai A et al. Influence of baseline and worsening renal function on efficacy of spironolactone in patients With severe heart failure: insights from RALES (Randomized Aldactone Evaluation Study). J Am Coll Cardiol 2012; 60: 2082-2089

27. Rossignol P, Dobre D, McMurray JJ et al. Incidence, determinants, and prognostic significance of hyperkalemia and worsening renal function in patients with heart failure receiving the mineralocorticoid receptor antagonist eplerenone or placebo in addition to optimal medical therapy: results from the Eplerenone in Mild Patients Hospitalization and Survival Study in Heart Failure (EMPHASIS-HF). Circ Heart Fail 2014; 7: 51-58

28. Charytan DM, Himmelfarb J, Ikizler TA et al. Safety and cardiovascular efficacy of spironolactone in dialysis-dependent ESRD (SPin-D): a randomized, placebo-controlled, multiple dosage trial. Kidney Int 2019; 95: 973-982

29. Hammer F, Malzahn U, Donhauser J et al. A randomized controlled trial of the effect of spironolactone on left ventricular mass in hemodialysis patients. Kidney Int 2019; 95: 983-991

30. Walsh M, Manns B, Garg AX et al. The safety of eplerenone in hemodialysis patients: a noninferiority randomized controlled trial. Clin J Am Soc Nephrol 2015; 10: 1602-1608

31. Felker GM, Lee KL, Bull DA et al. Diuretic strategies in patients with acute decompensated heart failure. N Engl J Med 2011; 364: 797-805

32. Testani JM, Damman K. Venous congestion and renal function in heart failure . . . it's complicated. Eur J Heart Fail 2013; 15: 599-601

33. Verbrugge FH, Martens $\mathrm{P}$, Ameloot $\mathrm{K}$ et al. Spironolactone to increase natriuresis in congestive heart failure with cardiorenal syndrome. Acta Cardiol 2019; 74: 100-107

34. Ahmad T, Jackson K, Rao VS et al. Worsening renal function in patients with acute heart failure undergoing aggressive diuresis is not associated with tubular injury. Circulation 2018; 137: 2016-2028

35. McMurray JJ, Packer M, Desai AS et al. Angiotensin-neprilysin inhibition versus enalapril in heart failure. N Engl J Med 2014; 371: 993-1004

36. Zhang $\mathrm{H}$, Huang $\mathrm{T}$, Shen $\mathrm{W}$ et al. Efficacy and safety of sacubitril-valsartan in heart failure: a meta-analysis of randomized controlled trials. ESC Heart Fail 2020; 7: 3841-3850

37. Swedberg K, Komajda M, Bohm M et al. Ivabradine and outcomes in chronic heart failure (SHIFT): a randomised placebo-controlled study. Lancet 2010; 376: 875-885

38. Tang AS, Wells GA, Talajic M et al. Cardiac-resynchronization therapy for mild-to-moderate heart failure. N Engl J Med 2010; 363: 2385-2395

39. Bardy GH, Lee KL, Mark DB et al. Amiodarone or an implantable cardioverter-defibrillator for congestive heart failure. N Engl J Med 2005; 352: 225-237

40. Jukema JW, Timal RJ, Rotmans JI et al. Prophylactic use of implantable cardioverter-defibrillators in the prevention of sudden cardiac death in dialysis patients. Circulation 2019; 139: 2628-2638

41. House AA, Wanner C, Sarnak MJ et al. Heart failure in chronic kidney disease: conclusions from a Kidney Disease: Improving Global Outcomes (KDIGO) Controversies Conference. Kidney Int 2019; 95: 1304-1317

42. Anker SD, Comin Colet J, Filippatos G et al. Ferric carboxymaltose in patients with heart failure and iron deficiency. $N$ Engl J Med 2009; 361: 2436-2448

43. Nguyen M, Rumjaun S, Lowe-Jones R et al. Management and outcomes of heart failure patients with CKD: experience from an inter-disciplinary clinic. ESC Heart Fail 2020; 7: 3225-3230

44. Lowe-Jones R, Junarta J, Salha A et al. The scope of a combined kidney failure-heart failure clinic. Future Healthc J 2019; 6: 104-104

45. Tormey V, Conlon PJ, Farrell J et al. Long-term successful management of refractory congestive cardiac failure by intermittent ambulatory peritoneal ultrafiltration. QJM 1996; 89: 681-683

46. Bertoli SV, Musetti C, Ciurlino D et al. Peritoneal ultrafiltration in refractory heart failure: a cohort study. Perit Dial Int 2014; 34: 64-70

47. Sánchez JE, Ortega T, Rodríguez C et al. Efficacy of peritoneal ultrafiltration in the treatment of refractory congestive heart failure. Nephrol Dial Transplant 2010; 25: 605-610 
48. Fröhlich H, Katus HA, Täger T et al. Peritoneal ultrafiltration in end-stage chronic heart failure. Clin Kidney J 2015; 8: 219-225

49. Viglino G, Neri L, Feola M. Peritoneal ultrafiltration in congestive heart failure-findings reported from its application in clinical practice: a systematic review. J Nephrol 2015; 28: 29-38

50. Chionh CY, Clementi A, Poh CB et al. The use of peritoneal dialysis in heart failure: a systematic review. Perit Dial Int 2020; 40: 527-539
51. Dukka H, Kalra PA, Wilkie M et al. Peritoneal ultrafiltration for heart failure: lessons from a randomized controlled trial. Perit Dial Int 2019; 39: 486-489

52. Ruhi Ç, Koçak H, Yavuz A et al. Use of peritoneal ultrafiltration in the elderly refractory congestive heart failure patients. Int Urol Nephrol 2012; 44: 963-969

Received: 5.10.2020; Editorial decision: 24.1.2021 